\title{
Assessment of Knowledge of Obstetric Danger Signs During Pregnancy Among Pregnant Mothers in Wolaita Sodo Hospitals and Sodo Town Health Centers in 2017
}

\author{
Tilahun Saol Tura* \\ Afflation: Department of Neonatology and Pediatric Nursing, College of Health Sciences and Medicine,Wolaita \\ Sodo University, Wolaita Sodo, Ethiopia \\ Masresha Assefa Demissie \\ Afflation: Department of Neonatology and Pediatric Nursing, College of Health Sciences and Medicine,Wolaita \\ Sodo University, Wolaita Sodo, Ethiopia
}

\begin{abstract}
Background: Pregnancy complications are the major health problems among women in developing countries. Approximately 529,000 women die from pregnancy related causes annually and almost all (99\%) of these maternal deaths occur in developing countries. Objective: To assess knowledge of pregnant mothers towards obstetric danger signs during pregnancy in Wolaita Sodo town health centers and hospital, April- May, 2017.Methods: Institutional based cross-sectional quantitative study was conducted in April-May,2017, on a sample of 365 mothers who are at least 4 months pregnant for prim gravid and multpara pregnant mothers selected from,11 urban Kebeles of Wolaita sodo town and simple random sampling technique was employed to select the study participants.Results: A total of 365 pregnant mothers were enrolled in the study giving a response rate of $100 \%$. The study participants from selected urban kebeles constituted $100 \%$. (46\%) of the study participants were found to have poor knowledge. Respondents who got obstetric danger signs information from health institution had 2 times good knowledge of obstetrics danger signs than those respondents who didn't get information from the same source. Participants who had formal education have 2.5 times knowledgeable than a participants who had informal education obstetric danger signs.Conclusion: Knowledge of study participants was assessed that 54\% of participants have knowledge about obstetric danger signs during pregnancy and only $34 \%$ have knowledge about obstetrics danger signs during labor and child birth.
\end{abstract}

Keywords: Danger signs, Pregnancy, Obstetric care.

DOI: $10.7176 / \mathrm{JHMN} / 65-01$

Publication date: August $31^{\text {st }} 2019$

\section{Background}

Pregnancy complications are the major health problems among women in developing countries. Approximately 529,000 women die from pregnancy related causes annually and almost all (99\%) of these maternal deaths occur in developing countries. The global maternal mortality is unacceptably high [1]. Although there was significant progress in all developing regions, the average annual percentage decline in the global maternal mortality ratio (MMR) was 3.1\%, short of the millennium Development Goals (MDGs) target of 5.5\%. Every day, almost 800 women still die due to pregnancy or child birth, and for every woman who dies 20 or more experience serious complications. One of the United Nations ${ }^{\text {ee }}$ MDGs is to reduce MMR by $75 \%$ by $2015^{[2]}$.

Developing countries account for $99 \%$ (284,000) of the global maternal deaths, the majority of which are in sub-Saharan Africa $(162,000)$ and Southern Asia $(83,000)$. These two regions accounted for $85 \%$ of global burden, with sub-Saharan Africa alone accounting for 56\%. The average maternal mortality ratio in developing countries in 2010 was 240 per 100,000 births versus 16 per 100,000 in developed countries reflecting inequities in access to health services, and highlighting the gap between rich and poor. Sub-Saharan Africa had the highest maternal mortality ratio at 500 maternal deaths per 100,000 live births. According to a systematic analysis of progress towards Millennium Development Goal 5 more than 50\% of all maternal deaths in 2008 were in only six countries (India, Nigeria, Pakistan, Afghanistan, Ethiopia, and the Democratic Republic of the Congo ${ }^{[3] \cdot}$ The situation in Ethiopia is similar to the situation in many developing countries. In Ethiopia the levels of maternal mortality and morbidity are among the highest in the world and the current estimate of MMR is 353per 100, 000 live births and it is reported that Maternal deaths accounted for $30 \%$ of all deaths to women age $15-49^{[4]}$. Reduction of mortality and morbidity of both mother and newborn have been identified as priority areas need urgent attention by the health sector. Maternal morbidity and mortality could be prevented and minimized significantly if women and their families recognize obstetric danger signs and promptly seek health care ${ }^{[5-6]}$. The commonest danger signs during pregnancy include severe vaginal bleeding, swollen hands/face and blurred vision. Key danger signs during labor and childbirth include severe vaginal bleeding, prolonged labor, convulsions, and retained placenta. Danger signs during the postpartum period include severe bleeding following childbirth, loss of consciousness after 
childbirth, and fever. Hemorrhage remains the leading cause of maternal mortality, accounting for approximately one third of deaths ${ }^{[7]}$. Many of the complications that result in maternal deaths contributing to prenatal deaths are unpredictable, and their onset can be both sudden and severe. The complications leading to maternal death can occur without warning at any time during pregnancy and childbirth ${ }^{[8]} \cdot$ Low awareness of danger signs and symptoms during pregnancy, labor, delivery and postpartum contribute to delays in seeking and receiving skilled care. Awareness of the danger signs of obstetric complications is the essential first step in accepting appropriate and timely referral to obstetric and newborn care. Knowledge of obstetric danger signs and birth preparedness are strategies aimed at enhancing the utilization of skilled care during low risk births and emergency obstetric care in complicated cases in low income countries. Increased knowledge and awareness is essential for reducing delays in seeking health care and in reaching a health facility. Communities and individuals should be empowered not only to recognize pregnancy related risks, but they must also have the means to react quickly and effectively once such problems arise ${ }^{[9-11]}$

The national reproductive strategy of Ethiopia has given emphasis to maternal and newborn health so as to reduce the high maternal and neonatal mortality. The strategy focuses on the need to empower women, men, families and communities to recognize pregnancy related risks, and to take responsibility for developing and implementing appropriate response to them. One of the targets in the strategies is to ensure that $80 \%$ of all families recognize at least three danger signs associated with pregnancy related complications by 2010 in areas where health extension program is fully implemented ${ }^{[12]}$.

\section{Statement of the problem}

Every minute, a woman dies due to causes related to pregnancy, childbirth and postnatal period ${ }^{[13]}$. Maternal deaths are avoidable, if women with complications are able to identify and seek appropriate emergency obstetric care which makes a difference between life and death ${ }^{[14]}$.

Maternal deaths have both direct and indirect causes. Around $80 \%$ of maternal deaths worldwide are brought about by direct obstetric complications the five major global causes of maternal death are:- severe bleeding (mostly bleeding postpartum), infections (also mostly soon after delivery), unsafe induced abortion, hypertensive disorders in pregnancy (eclampsia) and obstructed labour. Globally, about $80 \%$ of maternal deaths are due to these causes [6].

Hemorrhage alone accounts for one third of all maternal deaths in Africa, yet many of these deaths are preventable. Severe bleeding after birth can kill a healthy woman within two hours if she is unattended. Obstetric fistula resulting from obstructed labor is a long term complication suffered by as many as two million women (7).

Indirect causes such as malaria, diabetes, hepatitis, anemia and other cardiovascular disorders which are aggravated by pregnancy can also lead to maternal death ${ }^{[1,3]}$.Awareness of the danger signs of obstetric complications is the essential first step in accepting appropriate and timely referral to obstetric and newborn care. Raising awareness of women on danger signs of pregnancy, childbirth and the postpartum period improve mothers' attitude to seek medical care and is crucial for safe motherhood. ${ }^{(11)}$

When mothers do not recognize the danger signs in pregnancy, adverse effects can occur to the mother, the unborn baby, or the pregnancy itself. Adverse effects include: Illness or death of the mother, for instance, severe bleeding can lead to anemia or death of the mother, infection to the unborn baby through prematurely ruptured membranes, when amniotic fluid leaks from the vagina. If not attended to, this can lead to fetal or neonatal morbidity and mortality, termination of a pregnancy before term in vaginal bleeding (9).

Maternal hypertension or fever, can lead to increased numbers of neonatal deaths or prematurely born babies who may eventually die due to inadequate facilities to care for them ${ }^{[2]}$.A mothers' death in childbirth denies her children their natural, primary care giver and significantly increases the risk that her infant will die or fail to survive to age 5. A mothers' death also has an extremely detrimental effect on her children's access to education and health care. Many children who survive without mothers also risk being emotionally lost ${ }^{[1-3]}$. Most maternal deaths are avoidable, as the health care solutions to prevent or manage complications are well known. All women need access to antenatal care in pregnancy, skilled care during childbirth, and care and support in the weeks after childbirth. It is particularly important that all births are attended by skilled health professionals, as timely management and treatment can make the difference between life and death ${ }^{[1,2]}$.

According to the Ethiopian Federal Ministry of Health, only $10 \%$ of the deliveries is attended by health professionals. In one nation where the maternal mortality ratio is 353 per 100,000 live and IMR 51.1/1000 and NMR 27.7/1000 live births which are the highest in the world. In Ethiopia, there is little information about the knowledge of obstetric danger signs during pregnancy since the introduction of Health Extension Workers (HEWs), despite the national Reproductive strategy aim to raise the awareness to $80 \%$ in the area in which $\mathrm{HEW}$ are deployed [12].Studies conducted in Aleta Wondo district, indicated that the knowledge level of pregnant women about obstetric danger signs (during pregnancy, childbirth and postpartum period) was low and affected by residential area. Therefore, the identified deficiencies in awareness should be addressed through maternal and child health services by designing an appropriate strategies including provision of targeted information, education and 
communication. In spite of great potential of knowledge, attitude and practice of obstetric danger signs in reducing the maternal and newborn deaths its status are not well known in most of Sub-Saharan Africa including Ethiopia [15].

The study therefore aims to fill this gap by assessing the current status of knowledge of danger signs among mothers in the study area.

\section{Significance of the study}

As there is no adequate information on obstetric danger signs Knowledge, the study result will be vital and can be used as an input for maternal health curriculum, strategy and package establishment. This study will provide basic data on the issue that may help policy makers and as baseline data for $\mathrm{MOH}$ to reduce the highest maternal mortality rate of Ethiopia.

In addition to this, this study can have the following importance to different stake holders. The outcome of the study can be an input for concerned policy makers in decision making process regarding obstetric danger signs for pregnant and delivered mothers. And also it serves as an input for health education program undertaken by different organizations so as to keep the pregnant and delivered mothers being aware of the consequence of obstetric danger signs.

\section{OBJECTIVE}

$\checkmark \quad$ To assess knowledge of obstetric danger signs during pregnancy among mothers In Wolaita Sodotown Health centers and wolaita sodo teaching and referral hospital, SNNPR, Ethiopia April- May, 2017.

\section{METHODS AND MATERIALS}

Study area and period

The study was conducted in SNNPR, in Wolaita zone, Sodo town. WolaitaSodo town is $380 \mathrm{~km}$ and $156 \mathrm{~km}$ from Addis Ababa and Hawassa respectively. Sodo town is 82.1 square $\mathrm{km}$ and consists of 11 urban kebeles. The weather condition of the town is "dega" with mean annual temperature of 15.1 to 20 degree Celsius. The town is found within the latitude of 6.48 up to 6.53 north and longitude of 37.44 up to 37.46 east. The mean annual rain fall of the town is about 1200 to 1400 milt. The total population of the town is 121,538. Among which 64,149(52.8\%)are males and 57,389 (47.2\%) are females. WolaitaSodo town has 28,725 households. Among the women, 33,132 are in reproductive age group (15 to 49 years). There are various governmental, non-governmental and private health institutions in the town. There are two hospitals, three health centers, six health posts and thirty private clinics.

This study was conducted in 3 health centers and 1 governmental hospital in SNNPR,SODDO TOWN, from April- MAY, 2017

\section{Study design}

An institution based cross- sectional study design was conducted.

\section{Source population}

Women who were attending health centers and hospital at Sodo town within the study period in 2017.

Study population

All pregnant mothers who attend ANC follow up at Sodo town administration health centers and hospital which are included under study.

\section{Sample size determination}

The following assumptions were made to determine the sample size:

The formula to calculate the sample size ;

\section{$n=(z \alpha / 2)^{2} p(1-p) / D^{2}$}

Where $\mathrm{n}=$ number of the study subjects

$\mathbf{Z}=$ the standardized normal distribution curve value for the $95 \%$ confidence interval (1.96)

$\mathbf{P}=$ the level of Knowledge of obstetric danger signs during pregnancy in Tigray region the study areas which is

$61.1 \%$ have knowledge towards obstetrics danger signs during pregnancy.

$\mathbf{d}=$ the desired precision of the estimate (the margin of error between the sample and population, $5 \%$ )

$=(1.96)^{2} \times 0.611(1-0.611) /(0.05)^{2}$

$=365+18(5 \%$ None respondent rate $)=\mathbf{3 8 3}$ is the final sample size. 


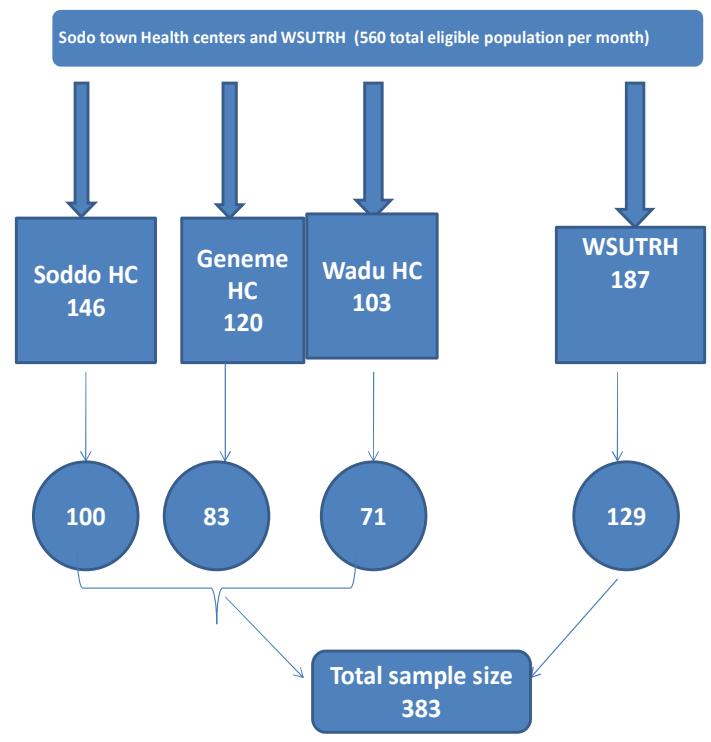

Figure 1 Schematic presentations of Sample allocationInclusion criteria and Exclusion criteria

Mothers who are mentally and physically capable of were interviewed and those who were volunteer to participate in the study were included and those mothers who were critically sick, pregnant health worker, mothers who are in labor and delivery service were excluded from study.

\section{Ethical clearance and consideration}

Ethical clearance letter was obtained from Research Ethics Committee (RIC) of Wolaita Sodo University health science and Medical College. Official letter of cooperation was obtained from WSU before conducting the interviews and observation was given to the participants and participants were assured of voluntary participation, confidentiality, anonymity and freedom to withdraw from the study at any time.

\section{Data collection and Data quality control}

Data collection tool: data collection was carried out by structured questionnaire which consisting of two parts: Socio demographic and knowledge towards obstetric danger sign The response was cared or written with pencil in provided space.

\section{Procedure for data collection}

Data collectors were interviewed the respondents and filled the questionnaires. The collectors were explained unclear questions if necessary during filling of the questionnaire. Finally, the filled questionnaires were collected by principal data collectors; it was tallied manually on tally sheet. The data was analyzed by using scientific calculator. Their statistically significance was assessed with the dependent variables. Finally using international and national data the result was compared, discussed and conclusion and recommendation was forwarded. The questionnaire was first Prepared in English and then translated into Amharic language for better understanding by respondents. The Amharic version of the questionnaire was then translated back to English language to check for its consistency.

Prior to the beginning of data collection each question was reached as to understand what variables were measured in each question and pretest was done by $10 \%$ of sample size. Questionnaires were reviewed for completeness at end of administering questions by group members. Students were cross checked the questionnaires for completeness every day.

\section{Data processing and analysis}

The collected data was checked for its completeness by investigators. The data was tallied using a tally sheet and analyzed manually using scientific calculator after its completeness checked. Then analyzed data was presented using table, charts and texts.

The nature of the study and associated risk and benefit was explained and then written consent was obtained for the participants.

\section{RESULTS}

\section{Socio-demographic characteristics of the study subjects}

A total of 365 pregnant mothers were enrolled in the study giving a response rate of $95.3 \%$. The study participants from selected urban kebeles were participated by volunteer respondents. The mean ages of the respondents were 28 years. $136(37.2 \%)$ of the participant were Orthodox, $190 \quad(52 \%)$ were protestant,29(8\%)were musilims, $10(2.8 \%)$ were others by religion. Majority, $356(97 \%)$ of the women were married and most $316(86.5 \%)$ 
of the respondents were wolaita by ethnicity. $188(51.5 \%)$ were housewives $.128(35 \%)$ had completed primary schoo,90(24.6\%)had completed secondary school. $101(27.7 \%)$ of the respondents had income between 1001 to 1500 birr during the study period. (See Table 1)

Table1: Distribution of socio-demographic and economic variables of respondents, of selected kebeles of wolaita sodo Town, 2017.

\begin{tabular}{|c|c|c|}
\hline Variable & Frequency & Percentages \\
\hline \multicolumn{3}{|l|}{ Age in years } \\
\hline $15-19$ & 50 & 13.7 \\
\hline $20-24$ & 122 & 33.4 \\
\hline $25-29$ & 120 & 32.9 \\
\hline $30-39$ & 68 & 18.6 \\
\hline$>40$ & 5 & 1.4 \\
\hline Total & 365 & 100 \\
\hline \multicolumn{3}{|l|}{ Marital Status } \\
\hline Single & 4 & 1.1 \\
\hline Married & 352 & 96.4 \\
\hline Widowed & 5 & 1.4 \\
\hline Divorced & 4 & 1.1 \\
\hline Total & 365 & 100 \\
\hline \multicolumn{3}{|l|}{ Religion } \\
\hline Orthodox & 136 & 37.3 \\
\hline Protestant & 190 & 52 \\
\hline Muslim & 29 & 8 \\
\hline Others & 10 & 2.7 \\
\hline Total & 365 & 100 \\
\hline \multicolumn{3}{|l|}{ Ethnicity } \\
\hline Wolaita & 316 & 86.5 \\
\hline Gamo & 22 & 6 \\
\hline Amhara & 9 & 2.5 \\
\hline Kambata & 7 & 2 \\
\hline Others & 11 & 3 \\
\hline Total & 365 & 100 \\
\hline \multicolumn{3}{|l|}{ Occupation } \\
\hline Housewife & 188 & 51.5 \\
\hline Governmental employ & 89 & 24.4 \\
\hline Private employ & 35 & 9.6 \\
\hline Own business & 53 & 14.5 \\
\hline Total & 365 & 100 \\
\hline \multicolumn{3}{|l|}{ Educational status } \\
\hline Not able to read and write & 30 & 8.2 \\
\hline able to read and write & 11 & 3 \\
\hline Primary School & 128 & 35.5 \\
\hline Secondary School & 85 & 23.3 \\
\hline Diploma & 79 & 21.6 \\
\hline Degree & 32 & 8.8 \\
\hline Total & 365 & 100 \\
\hline \multicolumn{3}{|l|}{ Monthly incomes } \\
\hline$<500$ & 69 & 19 \\
\hline $501-1000$ & 79 & 21.6 \\
\hline $1001-1500$ & 83 & 22.7 \\
\hline $1501-2000$ & 101 & 27.7 \\
\hline$>2000$ & 33 & 9 \\
\hline Total & 365 & 100 \\
\hline \multicolumn{3}{|c|}{ Time taken to reach the nearest health center? } \\
\hline 10-20 minutes & 162 & 44.4 \\
\hline 20-30 minutes & 203 & 55.5 \\
\hline Total & 365 & 100 \\
\hline
\end{tabular}




\section{Obstetric characteristics of the respondents}

From total number of respondents $291(79.7 \%$ ) had history of $2-4$ pregnancies and $35(5.5 \%)$ mothers were pregnant for more than four times. Regarding first pregnancy age mothers got their first pregnancy at 20-29years. From the total number of mothers 291(79.7\%) had 1-4 number of children. Regarding history of previous of pregnancy, 263(90.4\%) had ANC follow up, among those who had ANC follow up 253(96\%) had 4 visits and majority of mothers 347(95\%) properly receiving ANC follow up for current pregnancy. From those attended ANC $237(81.4 \%)$ gave birth at health institutions were $136(69 \%)$ of the study participants had got danger signs information from health personnel followed by media,friends and relatives with respective frequencies of $11.7 \%$, $10.7 \%$ and $8.6 \%$ respectively.

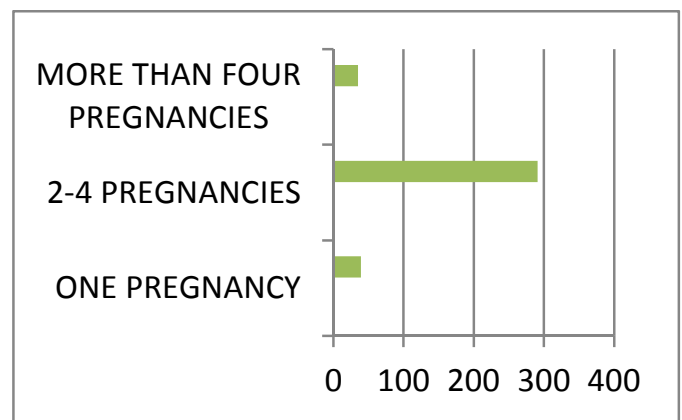

FIGURE 2 Total number of pregnancies among pregnant mothers who had ANC follow up at Sodo town administration health centers and hospitals, April_May, 2017.

\section{Obstetric danger signs Knowledge, during pregnancy, child birth and postnatal period in Wolaita Sodo} town.

Out of the 365 respondents, 197(54\%) reported that they had got information about obstetric danger sign during pregnancy. From those who had the information 78(39.6\%) identified severe vaginal bleeding at any time during pregnancy as danger sign while decreased or absence of fetal movement was indicated by $40(20.3 \%)$. Swelling of the body $25(12.7 \%)$, feeling of tired $17(8.6 \%)$, unusual abdominal pain $14(7.1 \%)$, persistent headache and blurred vision $12(6 \%)$, persistent back pain $11(5.6 \%)$ were also indicated by the study subjects as danger sign. Foul smelling vaginal discharge was mentioned by $11(5.6 \%)$ of the respondents and $14(7.1 \%)$ respondents mention other danger signs not mention here. (Table 2).

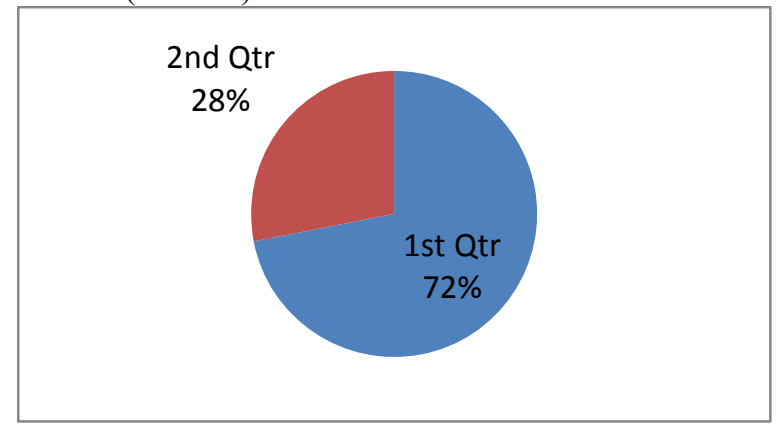

Figure 3: Knowledge of pregnant mothers who had ANC follow up at Sodo town administration health centers and hospitals, April-May, 2017. 
Table 2: knowledge of obstetric danger signs during pregnancy among pregnant mothers in wolaita Sodo town health centers and wolaita Sodo university teaching and referral hospital selected Kebeles of Wolaita Sodo town April-May, 2017.

\begin{tabular}{|c|c|c|c|}
\hline Variable & Category & Frequency & Percent \\
\hline \multirow[t]{3}{*}{ Heard of "obstetric danger signs during pregnancy } & Yes & 197 & 54 \\
\hline & No & 168 & 46 \\
\hline & Total & 365 & 100 \\
\hline \multirow{3}{*}{$\begin{array}{l}\text { Mentioned severe bleeding as danger sign during } \\
\text { pregnancy }\end{array}$} & Yes & 78 & 39.6 \\
\hline & No & 119 & 60.4 \\
\hline & Total & 197 & 100 \\
\hline \multirow{3}{*}{$\begin{array}{l}\text { Mentioned swelling of the body as danger sign } \\
\text { during pregnancy }\end{array}$} & Yes & 25 & 12.7 \\
\hline & No & 172 & 87.3 \\
\hline & Total & 197 & 100 \\
\hline \multirow{3}{*}{$\begin{array}{l}\text { Mentioned unusual abdominal pain as danger } \\
\text { sign during pregnancy }\end{array}$} & Yes & 14 & 7.1 \\
\hline & $\mathrm{NO}$ & 183 & 92.9 \\
\hline & Total & 197 & 100 \\
\hline \multirow{3}{*}{$\begin{array}{l}\text { Mentioned severe headache or blurred vision as } \\
\text { danger sign during pregnancy }\end{array}$} & Yes & 12 & 6 \\
\hline & No & 185 & 94 \\
\hline & Total & 197 & 100 \\
\hline \multirow{3}{*}{$\begin{array}{l}\text { Mentioned feeling very tired as danger sign } \\
\text { during pregnancy }\end{array}$} & Yes & 17 & 8.6 \\
\hline & $\mathrm{NO}$ & 180 & 91.4 \\
\hline & Total & 197 & 100 \\
\hline \multirow{3}{*}{$\begin{array}{l}\text { Mentioned absent or decreased fetal movement } \\
\text { as danger sign during pregnancy }\end{array}$} & Yes & 40 & 20.3 \\
\hline & $\mathrm{NO}$ & 157 & 79.7 \\
\hline & Total & 197 & 100 \\
\hline \multirow{3}{*}{$\begin{array}{l}\text { Mentioned persistent back pain as danger sign } \\
\text { during Pregnancy }\end{array}$} & Yes & 11 & 5.6 \\
\hline & No & 186 & 94.4 \\
\hline & Total & 197 & 100 \\
\hline \multirow{3}{*}{$\begin{array}{l}\text { Mentioned foul smelling vaginal discharge as } \\
\text { danger sign during pregnancy }\end{array}$} & Yes & 11 & 5.6 \\
\hline & $\mathrm{NO}$ & 186 & 94.4 \\
\hline & Total & 197 & 100 \\
\hline \multirow{3}{*}{$\begin{array}{l}\text { Mentioned high fever as danger sign during } \\
\text { pregnancy }\end{array}$} & Yes & 12 & 6 \\
\hline & $\mathrm{NO}$ & 185 & 94 \\
\hline & Total & 196 & 100 \\
\hline \multirow{5}{*}{$\begin{array}{l}\text { The source of information about obstetric danger } \\
\text { signs during pregnancy }\end{array}$} & Health personnel & 136 & 69 \\
\hline & Relatives & 17 & 8.6 \\
\hline & Friends & 21 & 10.7 \\
\hline & Media & 23 & 11.7 \\
\hline & Total & 197 & 100 \\
\hline \multirow{4}{*}{$\begin{array}{l}\text { Can any woman develop obstetric danger signs } \\
\text { during pregnancy? }\end{array}$} & Yes & 14 & 7 \\
\hline & No & 134 & 68 \\
\hline & Don’t know & 49 & 25 \\
\hline & Total & 197 & 100 \\
\hline
\end{tabular}




\begin{tabular}{|c|c|c|c|}
\hline Variable & Category & Frequency & Percent \\
\hline \multirow{3}{*}{$\begin{array}{l}\text { Is Information given about obstetric danger sign/s at } \\
\text { the clinic? }\end{array}$} & Yes & 150 & 76.1 \\
\hline & No & 47 & 23.9 \\
\hline & Total & 197 & 100 \\
\hline \multirow{3}{*}{$\begin{array}{l}\text { Experienced any obstetric danger sign during } \\
\text { pregnancy }\end{array}$} & Yes & 29 & 14.7 \\
\hline & No & 168 & 85.3 \\
\hline & Total & 197 & 100 \\
\hline \multirow{3}{*}{$\begin{array}{l}\text { Received antenatal care during last } \\
\text { pregnancy (For multi gravid and delivered mothers } \\
\text { only. }\end{array}$} & Yes & 263 & 90.4 \\
\hline & $\mathrm{NO}$ & 28 & 9.6 \\
\hline & Total & 291 & 100 \\
\hline \multirow{3}{*}{$\begin{array}{l}\text { Properly receive antenatal care during current } \\
\text { pregnancy }\end{array}$} & Yes & 347 & 95 \\
\hline & No & 18 & 5 \\
\hline & Total & 365 & 100 \\
\hline \multirow{6}{*}{$\begin{array}{l}\text { Number of antenatal visits during current } \\
\text { pregnancy }\end{array}$} & First & 54 & 14.8 \\
\hline & Second & 86 & 23.5 \\
\hline & Third & 103 & 28.2 \\
\hline & Fourth & 108 & 29.5 \\
\hline & $>$ Fourth & 14 & 4 \\
\hline & Total & 365 & 100 \\
\hline \multirow{4}{*}{$\begin{array}{l}\text { Place of delivery during last pregnancy (For multi } \\
\text { gravid and delivered mothers only). }\end{array}$} & Health center & 237 & 81.4 \\
\hline & Home & 41 & 14 \\
\hline & TBA & 13 & 4.6 \\
\hline & Total & 291 & 100 \\
\hline
\end{tabular}

\section{Knowledge on danger signs during child birth and postnatal period}

\section{Knowledge on danger signs during child birth}

Out of the 365 respondents, 124(34\%) reported that they had got information about obstetric danger during child birth and postnatal period. From those who had the information 52(42\%) identified severe vaginal bleeding at any time during child birth and postnatal period as danger sign, while prolonged labor 31(25\%), mali position $24(19.3 \%)$, retained placenta $17(13.7 \%)$, were indicated by respondents.

Table 3: knowledge of obstetric danger signs during child birth among pregnant mothers in Wolaita Sodo town health centers and Wolaita sodo university teaching and referral hospital Apri-May, 2017.

\begin{tabular}{|l|l|l|l|}
\hline Variable & Category & Frequency & Percent(\%) \\
\hline Have information about danger sign during labor and child-birth? & Yes & 124 & 34 \\
\cline { 2 - 4 } & NO & 241 & 66 \\
\cline { 2 - 4 } & Total & $\mathbf{3 6 5}$ & $\mathbf{1 0 0}$ \\
\hline \multirow{4}{*}{ Mentioned Sever vaginal bleeding as danger signs } & Yes & 52 & 42 \\
\cline { 2 - 4 } & NO & 72 & 58 \\
\cline { 2 - 4 } & Total & $\mathbf{1 2 4}$ & $\mathbf{1 0 0}$ \\
\hline \multirow{2}{*}{ Mentioned Prolonged labor as danger signs } & Yes & 31 & 25 \\
\cline { 2 - 4 } & NO & 93 & 75 \\
\cline { 2 - 4 } & Total & $\mathbf{1 2 4}$ & $\mathbf{1 0 0}$ \\
\hline \multirow{3}{*}{ Mentioned Mali position as danger signs } & Yes & 24 & 19.3 \\
\cline { 2 - 4 } & NO & 100 & 80.7 \\
\cline { 2 - 4 } & Total & $\mathbf{1 2 4}$ & $\mathbf{1 0 0}$ \\
\hline \multirow{2}{*}{ Mentioned Retained placenta as danger signs } & Yes & 17 & 13.7 \\
\cline { 2 - 4 } & NO & 107 & 86.3 \\
\cline { 2 - 4 } & Total & $\mathbf{1 2 4}$ & $\mathbf{1 0 0}$ \\
\hline
\end{tabular}


Table 4: knowledge of obstetric danger signs during postnatal period among pregnant mothers in wolaita sodo town health centers and wolaita sodo university teaching and referral hospital selected kebeles of Wolaita sodo town Apri-May, 2017.

\begin{tabular}{|l|l|l|l|}
\hline \multirow{2}{*}{$\begin{array}{l}\text { Heard information about danger sign during postnatal } \\
\text { period }\end{array}$} & Yes & 104 & $28.5 \%$ \\
\cline { 2 - 4 } & NO & 261 & $71.5 \%$ \\
\cline { 2 - 3 } & Total & 365 & $100 \%$ \\
\hline Mentioned Fever as danger signs & Yes & 21 & $20.2 \%$ \\
\cline { 2 - 3 } & NO & 87 & $79.8 \%$ \\
\cline { 2 - 3 } & Total & 104 & $100 \%$ \\
\hline \multirow{2}{*}{$\begin{array}{l}\text { Mentioned vaginal Bleeding as danger sins } \\
\text { Mentioned Offensive vaginal discharge as }\end{array}$} & Yes & 39 & $37.5 \%$ \\
\cline { 2 - 3 } \begin{tabular}{l} 
danger signs \\
\cline { 2 - 3 }
\end{tabular} & NO & 71 & $62.5 \%$ \\
\cline { 2 - 3 } $\begin{array}{l}\text { Mentioned Loss of consciousness as danger } \\
\text { signs }\end{array}$ & NO & 104 & $100 \%$ \\
\cline { 2 - 3 } & Total & 26 & $25 \%$ \\
\cline { 2 - 3 } & Nes & 104 & $75 \%$ \\
\cline { 2 - 3 } & Total & $100 \%$ \\
\hline
\end{tabular}

\section{DISCUSSION}

According to this study 54\% had heard obstetric danger signs and from those mothers about $150(76.1 \%)$ got information from clinic and it is less than the study done in Mekele that $79.6 \%$ respondents had information about danger signs of pregnancy (17). This difference might be due to socio-economic and geographical location. According to this study $69 \%$ of the study participants had got danger signs information from health personnel followed by media, friends and relatives with respective frequencies of $11.7 \%, 10.7 \%$ and $8.6 \%$ respectively was higher than the study done in Northern Nigeria, about a quarter of respondents in Birnin Gwari cluster and 13\% in Kunchi cluster indicated that danger sign songs in the media were the sources of information about safe motherhood. Over 10\% of women in Birnin Gwari cluster and almost 30\% in Kunchi cluster indicated that friends and neighbors were their sources of information of safe motherhood (37). The differences might be due to cultural and geographic location variations and the area where the study conducted.

Based on this study from those who had the information of obstetric danger signs $39.6 \%$ identified severe vaginal bleeding at any time during pregnancy which is lower than the findings in Aleta Wondo district $(45.9 \%)$ (15), higher than the findings in Burkina Faso (39.4\%) and Guatemala $(31.0 \%)(38,39)$. This difference might be due to socio-cultural difference and difference of sample size used. According to this study $46 \%$ of the study respondents were unable to mention an obstetric danger sign which is more than the study done in Aleta Wondo district $39.1 \%$ and Tsegedie district $35.1 \%$ and $(15,16)$. The differences might be due to socio economic and health education provided.

This study revealed that the respondentse occupation, educational level, monthly income, first pregnancy age, having ANC follow up, time to nearest health facility, source of information and place of residence were significantly associated with knowledge of obstetric danger signs during pregnancy.

It was found that residence had significant association with knowledge of obstetric danger signs during pregnancy that urban residents had 2.2 times good knowledge than rural respondents [2.2). This is greater than the study done in Aleta Wondo(15).

Based on this study it was found that the study respondents' occupation was significantly associated with obstetric danger signs knowledge of the respondents: those respondents who were government employee had 2.1 times good knowledge than housewives. It is less than the study done in Egypt (8) found that occupation appeared to influence women's awareness of danger signs of obstetric complications. However, this finding is contrasted with study done in rural Tanzania (19).

In this study, the respondentse educational level seems to play a role in having knowledge of obstetric danger signs that respondents who have had formal education had 2.1 times good knowledge than who have informal education and respondents who have had high level education had 3 times good knowledge than those respondents with informal education. This study is similar with the study done in Egypt (8) and rural Tanzania (19) which found that women with higher levels of education were more aware of danger signs of obstetric complications than women with lower or no formal education. This study found no statistically significant difference in knowledge of danger signs of obstetric danger signs with respondent's number of ANC visits, similar to the study done in Tanzania (19), Pembe et al (2009:6) found that women who made four or more ANC visits were more aware of danger signs of obstetric complications than those who made less than four ANC visits, independent of gestational age at booking. This difference might be due health education given during ANC follow up. 


\section{CONCLUSION}

Based on this study finding majority of mothers had got information about obstetric danger sign different areas but few mothers have knowledge about the complications of obstetric danger signs and its severity. are significantly associated with obstetric danger signs knowledge.

The researcher recommend that concerned body should act to increase the knowledge of the community regarding obstetric danger sign.

Researcher recommend also other scholars to conduct in this area because this research only describes the reality but it does not show the factor associate with it

\section{Acknowledgement}

First of we would like to thank Almighty God. Also we would like acknowledge our friends and senior staff who helped us during of this article preparations.

\section{Declaration:}

We declare that this article is our original work. It was not copied from any other research and all references used for the preparation of this article were cited properly. Regarding fund of research; it was fully covered by researchers.

\section{REFERENCES}

1. UNICEF. A Global Overview of Maternal Mortality.2010

2. UNFPA. Safe Motherhood Stepping up Efforts to Save Mothers ${ }^{\text {ee }}$ Lives 2011.

3. WHO. Trends in Maternal Mortality: 1990 to 2010, WHO, UNFPA, UNICEF and World Bank. Geneva 2012.

4. Central Statistical Agency and ORC Marco. Ethiopian Demographic and Health Survey, 2011. Addis Ababa, Ethiopia and Calverton, Maryland, USA; 2012.

5. Thaddeus S, Maine D. Too far to walk: maternal mortality in context. Social Science Medicine 1994; 38: 10911110

6. Jackson D. Loveday M, Doherty T, Mbombo N, Wington A, Matizirifa L,et al. Community Based Situation Analysis: Maternal and Neonatal Follow-up Care. Durban: Health Systems Trust.2006. p. 9-13.

7. Dutta DC. Text Book of Obstetrics. 6th ed. Calcutta: New Central Book Agency (P) Ltd; 2004.p. 121-124.

8. Rashad WA, Essa RM.Womenes Awareness of Danger Signs of Obstetrics Complications in Egypt. Journal of American Science 2010; 6(10): 1299-1306.

9. Kabakyenga JK, Ostergren PO, TuryakiraE,Pettersson K. Knowledge of obstetric danger signs and birth preparedness practices among women in rural Uganda. BMC pregnancy and Child birth 2011,11: 73

10. Mihret H, Mesganaw F: Birth preparedness and complication readiness among women in Adigrat town, northern Ethiopia. EthiopJHealth Dev 2008, 22(1):14-20.

11. JHPIEGO. Monitoring birth preparedness and complication readiness: tools and indicators for Maternal and Newborn health Baltimore.2004.

12. Federal Democratic Republic of Ethiopia, Ministry of Health. National Reproductive Strategy, 2006-2015. Addis Ababa, Ethiopia: FMOH; 2006.p. 16-21.

13. Abouzahr C. Safe Motherhood:a brief history of the global movement. World Health Organization, Geneva, Switzerland 1947-2002.

14. WHO. Why do so many women still die in pregnancy or childbirth? 2005.

15. Mesay Hailu et al, knowledge about obstetric danger signs among pregnant women in Aleta Wondo district, Sidama zone, Southern Ethiopia. Ethiopian Journal of Health Development 2007; 20(1); 25-32. p43

16. Hailu D, Berhe H (2014) Knowledge about Obstetric Danger Signs and Associated Factors among Mothers in Tsegedie District, Tigray Region, Ethiopia

17. Gebrehiwot et al. Awareness of Danger Signs of Pregnancy and its Associated Factors among Pregnant Women who Visit ANC in Mekelle Public Hospitals, 2014.

18. USAID. Family Planning and Reproductive Health Indicators Database. Existence of a safe motherhood strategic plan to promote access and quality of safe motherhood services. Measure Evaluation Population and Reproductive health 2010.

19. Pembe et al: Rural Tanzanian women "es awareness of danger signs of obstetric complications.BMC Pregnancy Child birth March 2009, 9; 12 .

20. Nepal. Improving Maternal, Newborn and Child Health in the South East Asia Region. 2005. p. 63.

21. Perreira KM,Bailey PE, De Bocaletti E, Hurtado E, Recinos de Villagran S, Matute J, Increasing awareness of danger signs in pregnancy through community and clinic based education in Guatemala. Maternal Child Health Journal 2002; 6(1): 19-28.

22. Urassa DP, Pembe AB and Mganga F. Birth preparedness and complication readiness among women in Mpwapwa district, Tanzania. Tanzania Journal of Health Research January 2012; 14(1): 3-6 
23. Ali AA, Rayis DA, Abaker AO, Adam I. Awareness of danger signs and nutritional education among pregnant women in Kassala, Eastern Sudan. Sudanese Journal of Public Health 2010; 5(4): 179-181.

24. Alam AY,Qureshi AA, Adil MM, Ali H. Comparative study of Knowledge, Attitude and Practices among Antenatal Care Facilities utilizing and non- utilizing women in Islamabad. Journal of Pakistan Medical Association 2004; 55(2): 2-4.

25. Anya SE, Hydara A, Jaiteh LES. Antenatal care in The Gambia: Missed opportunity for information, education and communication. BMC Pregnancy and Childbirth 2007, 8:9.

26. Agboatwalla M, Akram DS. Impact of Health education on mothers ${ }^{\text {ee }}$ knowledge of preventive health practices, Karachi Pakistan. PubMed Journal of Pakistan Medical Association 1997; 27(4): 199- 202.

27. Cham M, Sundby J, Vangen S. Maternal mortality in rural Gambia, a qualitative study on access to emergency obstetric care BMC Reproductive Health 2005; 2:3.44

28. Sarode VM. Does illiteracy influence pregnancy complications? Among women in the slums of greater Mumbai. International Journal of Sociology and Anthropology 2010; 2(5): 82-94.

29. WHO. Maternal, Neonatal, and child health. Strategy Global Health program 2009.

30. Nikiema B, Beninguisse G, Haggerty JL.Providing information on pregnancy complications during antenatal visits: unmet educational needs in sub- Saharan Africa. Health policy and planning 2009; 34: 370-374.

31. Chongo C. A study to determine knowledge attitude and practice of women in child bearing age towards danger signs in pregnancy in Lusaka, urban Lusaka 1885.

32. Marco A. Knowledge and practice of maternal health care in Indonesia 2003.

33. I. J. Hasan, N. Nisar. Women "s Perceptions regarding Obstetric Complications and Care in a Poor Fishing Community in Karachi, 1999.

34. Making pregnancy and childbirth safer. (1997) Policy Brief. Washington, DC: USA World Population reference bureau. Available: www.measurecommunication.org.

35. World health organization. (2005) make every mother and child count. Switzerland: World Health Organization. Available: http://www.who.int/Whr/ 2005/ hr 2005 en.pdf.

36. Debre Birhan Woreda Health Office (2013 report).

37. Okereke et al. Reproductive Health 2013, 10:57. Knowledge of safe motherhood among women in rural communities in northern Nigeria: implications for maternal mortality reduction.

38. Baya B, Sangli G, Maiga A. Measuring the effects of behavior change interventions in Burkina Faso with population-based survey results. Maryland, USA: JHPIEGO; 2004

39. Becker F, Y.glesias C. Measuring the effects of behavior change and service deliver interventions in Guatemala with population-based survey. Maryland, USA:JHPIEGO; 2004. 